DOI 10.37882/2500-3682.2021.08.04

\title{
ЭКСПЕРИМЕНТАЛЬНОЕ ИССЛЕДОВАНИЕ НАДЕЖНОСТИ ГРУППЫ В СОВМЕСТНОЙ СПОРТИВНОЙ ДЕЯТЕЛЬНОСТИ
}

\section{EXPERIMENTAL STUDY OF THE GROUP'S RELIABILITY IN JOINT SPORTS ACTIVITIES}

I. Demin

Summary: The purpose of the study was to study the socio-psychological conditions of the reliability of small groups in joint sportive activity. The object of the study was joint sports activity as part of a small social group in the conditions of training and competitions. The actualization of the reliability of small social groups in the tense conditions of joint activity is due to the level of organization of these groups. The empirical basis of the study was made up of small sports groups. A total of 25 small groups participated in the study. The article presents the program and results of an experimental study of the reliability of small groups in joint sports activities. It is shown that the main indicators of the reliability of sports teams in competition conditions are determined by the level of organization of the group.

Keywords: reliability, small group, joint activity, standard and stressful conditions of activity, organization, experiment.

\author{
Демин Игорь Владиславович \\ старший преподаватель, ФГБОУВО «Курский \\ государственный университет» \\ dema-7@yandex.ru
}

Аннотация: Цель исследования заключалась в том, чтобы изучить социально-психологические условия надёжности малых групп в совместной спортивной деятельности. В качестве объекта исследования выступала совместная спортивная деятельность в составе малой социальной группы в условиях тренировок и соревнований. Актуализация надежности малых социальных групп в напряженных условиях совместной деятельности обусловлена уровнем организованности этих групп. Эмпирическую базу исследования составили малые спортивные группы. Всего в исследовании участвовало 25 малых группы. В статье представлена программа и результаты экспериментального исследования надежности малых групп в совместной спортивной деятельности. Показано, что основные показатели надежности спортивных команд в условиях соревнований детерминировано уровнем организованности группы.

Ключевые слова: надежность, малая группа, совместная деятельность, стандартные и напряженные условия деятельности, организованность, эксперимент.

\section{Программа экспериментального исследования}

Цель исследования заключалась в том, чтобы изучить социально-психологические условия надёжности малых групп в совместной спортивной деятельности. В качестве объекта исследования выступала совместная спортивная деятельность в составе малой социальной группы в условиях тренировок и соревнований. Предмет исследования - социально-психологические условия актуализации надёжности малых спортивных групп в совместной деятельности в напряжённых условиях. Гипотеза исследования заключалась в предположении о том, что актуализация надежности малых социальных групп в напряженных условиях совместной деятельности обусловлена уровнем организованности этих групп.

Эмпирическую базу исследования составили малые спортивные группы. Всего в исследовании участвовало 25 малых группы - 14 мужских спортивных команд и 11 женских (всего 206 человек, в том числе 113 лиц мужского пола, 93 лица женского пола). Возраст испытуемых - от 17 до 22 лет.

Методы исследования включали наблюдение, беседу, бланковые и психодиагностические методики, в том числе: методика В.А. Хащенко «Зрительно-аналоговая шкала» (ЗАШ) [6], «Карта-схема психолого-педагогической 
характеристики группы» [9], «Методика для экспертной оценки согласованности действий» С.В. Сарычева [4 с. 164-165; 94], «Методика для экспертной оценки взаимодействия» С.В. Сарычева [4, с. 162-164]. Для исследования надёжности групп в лабораторных условиях использовался прибор-модель совместной деятельности «Арка» [8].

В соответствии с гипотезой и целью исследования нами была выработана общая стратегия исследования надёжности малых социальных группы в совместной спортивной деятельности (стандартных и напряженных условиях). В данном исследовании нам представляется целесообразным сочетать разные группы эмпирических методов исследования: эксперимент, наблюдение, опросные методы, аппаратурные методы.

Формой организации исследования нами был избран лабораторный и естественный социально-психологический эксперимент. При исследовании надёжности группы в напряженных условиях совместной деятельности целесообразно в качестве главного метода организации исследования использовать естественный эксперимент, позволяющий изучить спортивные группы в реальных напряженных условиях (в условиях соревнований). Его необходимо дополнить лабораторным экспериментом, что позволит выделить изучаемые психологические явления «в чистом виде» и уточнить данные, полученные в естественном эксперименте.

Положения, приведенные выше, явились основополагающими для конструирования методического блока, использованного нами для экспериментального исследования надёжности группы в напряженных условиях совместной деятельности. В рамках социально-психологического эксперимента мы использовали прибормодель совместной деятельности «Арка», позволяющий актуализировать процесс и свойства совместной деятельности группы.

В лабораторном эксперименте мы отвели приоритетное место моделированию совместной деятельности группы с помощью «Арки». Для обеспечения корректности исследования и сравнимости данных о группах с различной степенью организованности нужно было разделить группы по признаку организованности, которая согласно гипотезе исследования выступала в качестве независимой экспериментальной переменной.

Мы воспользовались типологией организованности групп, предложенной А.С. Чернышевым [11], согласно которой выделяются три типа групп. Основные показатели организованности измерялись с применением «Карты-схемы психолого-педагогической характеристики группы», разработанной Л.И. Уманским, А.С. Чернышевым, А.Н. Лутошкиным и др. [9, с. 256-263].
Измерение основных показателей осуществлялось в стандартных и напряженных условиях совместной деятельности, каждый из показателей соотнесен нами с определенными в «Карте-схеме» квантами. Степень проявления каждого наблюдаемого проявления жизнедеятельности группы оценивается по пятибалльной шкале, вмонтированной в «Карту-схему».

По каждому из показателей определялось значение моды (М0). «Карта-схема» использовалась и как основа для монографического наблюдения за жизнью и деятельностью спортивных групп в естественном и лабораторном эксперименте, и как основа для экспертной оценки этих групп. Все исследуемые группы были оценены экспертами. В качестве экспертов выступали тренеры, работающие с данной командой, представители администрации. Каждую группу оценивали не менее пяти экспертов.

В качестве показателя организованности групп мы использовали также психологический настрой на совместную деятельность. Данный показатель измерялся с помощью прибора-модели «Арка», актуализирующего именно этот показатель в наибольшей степени. Величина психологического настроя определяется по соответствующей формуле [8].

С помощью данной методики можно изучить влияние группового статуса на самочувствие ее членов, их общественную активность и гуманизацию межличностных отношений в группе. «Арка» предназначена для предъявления групповой задачи, требующей дружного, согласованного практического действия группы людей в составе от 2 до 20 человек. В 1980-90 гг. А.С. Чернышевым, Ю.А. Луневым, С.В. Сарычевым и А.В. Корневым были разработаны модификации экспериментальных процедур работы с «Аркой» [7; 12].

Из этих модификаций мы использовали: деятельность в особо мотивированных условиях («на рекорд»); деятельность в условиях лимита времени («отсчет времени»); деятельность в условиях исключения или замены одного из членов группы.

Важным показателем организованности является единство мнений $[10$, с. 29], которое измерялось нами по методике «Зрительно-аналоговая шкала [6]. Обработка данных предполагает измерение полученных оценок с помощью линейки, вычисление средних групповых показателей по каждой шкале, сопоставление индивидуальных показателей со средними групповыми, вычисление среднего линейного отклонения. Методика применялась разработчиками как в естественном, так и в лабораторном эксперименте $[1 ; 5 ; 13]$.

В соответствии с логикой экспериментального иссле- 
дования, гипотезой, целями, задачами и предметом исследования, были определены его основные параметры. Предметом экспериментального исследования является надёжность группы в напряженных условиях совместной деятельности, выступающая в нашем исследовании в качестве зависимой экспериментальной переменной. В качестве независимой экспериментальной переменной в осуществленном нами исследовании уровень организованности группы.

\section{Результаты исследования}

Измерения значений показателя «результативность» в стандартных и напряженных условиях совместной деятельности, анализ которых позволяет придти к заключению о расширении диапазона возможных исходов результативности совместной деятельности в напряженных условиях по сравнению с оптимальными.

Данные исследования показывают, что по эмпирическому референту «наличие и качество плана» существуют значительные отличия групп среднего уровня организованности, как от высокоорганизованных групп, так и от групп с низким уровнем организованности. Главное отличие проявляется в степени количественной выраженности данного эмпирического референта у групп среднего уровня организованности. Это характерно как для стандартных, так и для напряженных условий совместной деятельности.

Среднеорганизованные группы в процессе ориентировки вырабатывают лишь частичную ориентировочную основу предстоящей совместной деятельности, что негативно сказывается на продуктивности и безотказности. Расхождения плана с действиями в этих группах существенные, предпринимаемые действия во многом спонтанны.

Попытки согласования, упорядочения действий в напряженных условиях совместной деятельности групп низкого уровня организованности имеют противоположный эффект тому, который проявляется у всех высокоорганизованных групп и большинства групп среднего уровня организованности. В стандартных условиях совместной деятельности план либо отсутствует, либо его качество низкое.

Характеризуя показатель «согласованность действий» групп низкого уровня организованности, можно сказать, что в стандартных условиях совместной деятельности уровень его столь же невысок, как и в напряженных условиях. У большинства групп в особомотивированной деятельности в напряженных условиях совместной деятельности по основным эмпирическим референтам согласованности действий еще ниже. Для групп такого рода даже стандартные условия совмест- ной деятельности представляют собой препятствие в плане согласования действий по достижению общего результата, которое группа не способна преодолеть посредством выработки плана действий предстоящей совместной деятельности, согласованием действий и реализацией плана.

В напряженных условиях совместной деятельности для групп низкого уровня организованности характерно отсутствие заранее продуманного способа взаимодействия, готовности проявить инициативу в плане изменения взаимодействия, пассивное ожидание помощи от других членов группы. В результате взаимодействие оказывается негибким, ригидным, закостеневшим в «старых формах», которые привычны для членов группы.

Группа низкого уровня организованности оказывается не властной над способом взаимодействия, не способна провести его изменение в соответствии с теми требованиями, которые перед группой ставят внешние и внутренние условия деятельности. Изменение взаимодействия происходит как бы само по себе, вне зависимости от намерений членов группы.

Эмпирический референт «самостоятельность и инициативность во взаимодействии» у групп низкого уровня организованности имеет низкий уровень выраженности. Инициатива во взаимодействии у групп высокого уровня организованности исходит от многих членов группы, не замыкается на отдельных лицах.

Инициативное поведение большинства членов высокоорганизованных групп постоянно соотносится с групповыми целями, возможностями группы. По эмпирическому референту «вариативность и иерархия взаимодействия» группам высокого уровня организованности в напряженных условиях совместной деятельности присуще сохранение уровня выраженности данного референта. Качественное своеобразие проявления данного референта в напряженных условиях совместной деятельности заключается в соотнесении членами группы мотивации группы на внесение изменений во взаимодействие с общегрупповой целью достичь наилучшего результата в совместной деятельности, образ которой заранее создается членами группы.

Мы установили, что инициатива в этих группах исходит не только от узкого круга лидеров, но и от других членов группы. Существенно и то, что высокоорганизованные группы мотивированы на принятие инициативы любого члена группы, если инициатива соответствует целям группы, учитывает возможности ее членов, особенности ситуации совместной деятельности группы. Кроме того, у групп этого типа проявляется связь между инициативностью и вариативностью взаимодействия, заключающаяся в том, что высокоорганизованная груп- 
па, опираясь на инициативные предложения любого из членов, желает и способна изменить взаимодействие в соответствии с теми целями, которые перед ней стоят.

Итак, спортивные группы высокого уровня организованности в напряженных условиях совместной деятельности выполняют совместную деятельность безотказно, с минимальным разбросом лучших и худших результатов. Это наиболее типично для особомотивированной деятельности в напряженных условиях.

Однако и в обычной деятельности в напряженных условиях уровень безотказности весьма высок (91\% заданий выполняется безотказно). Основные эмпирические референты результативности изменяются согласованно. Уровень их выраженности коррелирует со степенью напряженности условий совместной деятельности группы: чем выше степень напряженности условий совместной деятельности, тем меньше отказов, выше продуктивность, меньше разброс максимальных и минимальных результатов. В результативности высокоорганизованных групп как бы синтезируются позитивные стороны групп средней и низкой организованности: повышение продуктивности и повышение безотказности в напряженных условиях совместной деятельности.

Члены высокоорганизованных групп придают большое значение согласованию коллективных действий, кропотливой разработке проекта грядущей совместной деятельности. Ориентировочная часть общей деятельности в напряженных условиях располагает большим удельным весом, чем в стандартных условиях.

Содержательная область проекта грядущей совместной деятельности в напряженных условиях улучшается по сравнению с условиями стандартными. Свойство подобного проекта характеризуется тщательным распределением функций, возможностью любого члена группы доказать необходимость распределения функций, устойчивостью самого плана. значительную роль в согласовании совместной деятельности играют лидеры высокоорганизованных групп, их видение ожидающей и протекающей совместной деятельности «концептуально», они видят обстановку в целом.

Группы высокого уровня организованности в напряженных условиях совместной деятельности характеризует полнота соотношения совместной деятельности плану, разработанному в ориентировочной доле деятельности. Это сочетается со способностью группы вносить коррективы в план в согласовании с модифицирующимися условиями. В напряженных условиях совместной деятельности подобные группы готовы к произвольной саморегуляции совместной деятельности в согласовании с идеальным образом результата и хода совместной деятельности.
Согласование в высокоорганизованных группах в напряженных условиях совместной деятельности ориентировано на деловую интеграцию группы, действия членов группы устремлены на ключевых обстоятельствах взаимодействия, необходимых для достижения групповых целей. Члены подобных групп испытывают нужду и готовы к изменению взаимодействия из-за достижения оптимального вероятного результата.

В напряженных условиях они устремляются к созданию более абсолютной формы порядка совместной деятельности за счет перестройки взаимодействия. Предельное значение ключевых экспериментальных референтов достигается в особомотивированной деятельности в интенсивных условиях, притом члены подобных групп устремляются реализовать точный учет вероятных последствий от изменений, вносимых во взаимодействие.

Динамика ключевых экспериментальных референтов результативности у групп не носит скоординированного характера, противоречива. Группы данного типа, тем не менее, готовы к увеличению продуктивности совместной деятельности в напряженных условиях (только в особомотивированной деятельности), только ценой роста разброса лучших и худших показателей результативности и снижения безотказности. эффективность становится непрогнозируемой в интенсивных условиях совместной деятельности.

Низкоорганизованным группам свойственно преимущество исполнительской доли совместной деятельности над ориентировочной долею и в оптимальных, и в интенсивных условиях. В напряженных условиях совместной деятельности по сопоставлению с типовыми условиями уменьшится удельный вес ориентировки в структуре совместной деятельности.

План предстоящей совместной деятельности отсутствует либо характеризуется низким качеством. Если даже план имеется, то в интенсивных условиях уровень выраженности экспериментального референта «соответствие деятельности плану» снижается.

Таким образом, увязка действий и функций осуществляется стихийно, члены низкоорганизованных групп не стремятся к их упорядочению и согласованию и в стандартных, и в напряженных условиях совместной деятельности. Взаимодействие в интенсивных условиях совместной деятельности не соотносится ни с групповыми целями, ни с возможностями группы.

Уровень выраженности взаимодействия постоянно низок в стандартных и в напряженных условиях совместной деятельности. Вследствие неимения предварительно продуманного способа взаимодействия, его 
оптимизация в напряженных условиях для низкоорганизованных групп не осуществима.

В напряженных условиях уровень самодостаточности и инициативности членов групп данного типа опускается по сравнению со стандартными условиями (наиболее явно - в особомотивированной совместной деятельности). Полная включенность во взаимодействие в напряженных условиях совместной деятельности замечена нами только у незначительного числа членов низкоорганизованных групп, причем полнота включенности уменьшится с возрастанием уровня напряженности ситуации совместной деятельности. предельная включенность во взаимодействие отмечается в особомотивированной совместной деятельности.

\section{Зак^ючение}

Таким образом, экспериментальное исследование доказало выдвинутую гипотезу. Полученные итоги позволили сформулировать следующие выводы: достоверность спортивных групп в интенсивных условиях совместной деятельности детерминирована организованностью.

1. Группы разного уровня организованности характеризуются разной динамикой ключевых показателей надежности в напряженных условиях совместной деятельности.
2. Причинно-следственная связь между надежностью и организованностью по своему характеру не является линейной, а носит сложный и опосредованный характер.

3. Выступая в свойстве опосредующего звена надёжности, организованность качественно предает содержание ключевых характеристик надежности в интенсивных условиях совместной спортивной деятельности группы. По своему психологическому содержанию надежность выступает как система групповых мотивов и социальных конструкций на улучшение системы совместной деятельности группы в интенсивных условиях.

4. Существуют веские отличия по степени выраженности и по динамике ключевых характеристик надежности в напряженных условиях групп различного уровня организованности в зависимости от формы организации совместной деятельности.

5. Качественной спецификой надежности в интенсивных условиях спортивных групп среднего и высокого уровня организованности является полная безотказность в особомотивированной деятельности.

6. Различные группы (даже в рамках одного типа) характеризуются различной динамикой и соотношением, степенью выраженности разнообразных психологических механизмов надежности, «индивидуальными» психологическими свойствами группы.

\section{ЛИТЕРАТУРА}

1. Дука А.И. Исследование характеристик надежности как социально-психологического качества групп инкассаторов / А.И Дука, Е.А. Болотова // Вестник Красноярского государственного педагогического университета им. В.П. Астафьева. - Вып. 2 (36). - 2016. - С.119-124.

2. Надёжность и быстродействие человеко-машинных систем. - Ростов-на-Дону : Изд-во Ростовского университета, 1983. - 144 с.

3. Сарычев С.В. Исследование надёжности малых групп в социально-психологическом эксперименте / С.В. Сарычев // Российский психологический журнал. - 2007. - №3. - Т. 4. - С. 21-34.

4. Сарычев С.В. Социально-психологические аспекты надёжности группы в напряженных ситуациях совместной деятельности / С.В. Сарычев, А.С. Чернышев. - Курск : Изд-во КГПУ, 2000. - 180 с.

5. Сарычев С.В. Социально-психологические факторы надёжности малых групп в различных социальных условиях : дис. ... д-ра психол. наук : 19.00 .05 / С.В. Сарычев. - Курск, 2008. -259 с.

6. Хащенко, В.А. Программа комплексного исследования жизнедеятельности личности и группы в экстремальных условиях / В.А. Хащенко // Методики психологической диагностики личности и группы. - М. : ИП АН СССР, 1990. - С. 150-190.

7. Чернышев, А.С. Аппаратурная методика «Арка» : диагностика малой группы в совместной деятельности : методическое руководство / А. С. Чернышев, С. В. Сарычев. - Санкт-Петербург : ИМАТОН, 2016. - 55 с.

8. Чернышев, А.С. Аппаратурные методики психологической диагностики группы в совместной деятельности / А.С. Чернышев, С.В.Сарычев, Ю.А. Лунев. М. : Изд-во «Ин-т психологии РАН», 2005. - 189 с.

9. Чернышев, А.С. Психологическая школа молодежных лидеров / А.С. Чернышев, Ю.А. Лунев, Ю.Л. Лобков, С.В. Сарычев. - М., 2005. - 275 с.

10. Чернышев, А.С. Социально-психологические основы организованности пер-вичного коллектива (на материалах исследования молодежных групп и коллективов) : автореф. дисс. ... д-ра психол. наук : 19.00 .05 / А.С. Чернышев. - М., 1980. - 65 с.

11. Чернышев, А.С. Социально-психологические основы работы классного руководителя / А.С. Чернышев, А.С. Крикунов, А.И. Луньков. - М. : Просвещение, 1989. -107 c.

12. Чернышев, А.С. Экспериментальная методика изучения межгруппового взаимодействия / А.С. Чернышев, Ю.А. Лунев, С.В. Сарычев, А.В. Корнев // Методики социально-психологической диагностики. - М. : ИП АН СССР, 1990. - С. 162-170. 
13. Gamova, E.I. Socio-psychological problems of the prevenient part of joint activities in youth small groups / E.I. Gamova, S.V. Sarychev // Problems of education in 21st century. - Vol. 18. - P. 60-65.

() Демин Игорь Владиславович (dema-7@yandex.ru).

Журнал «Современная наука: актуальные проблемы теории и практики»

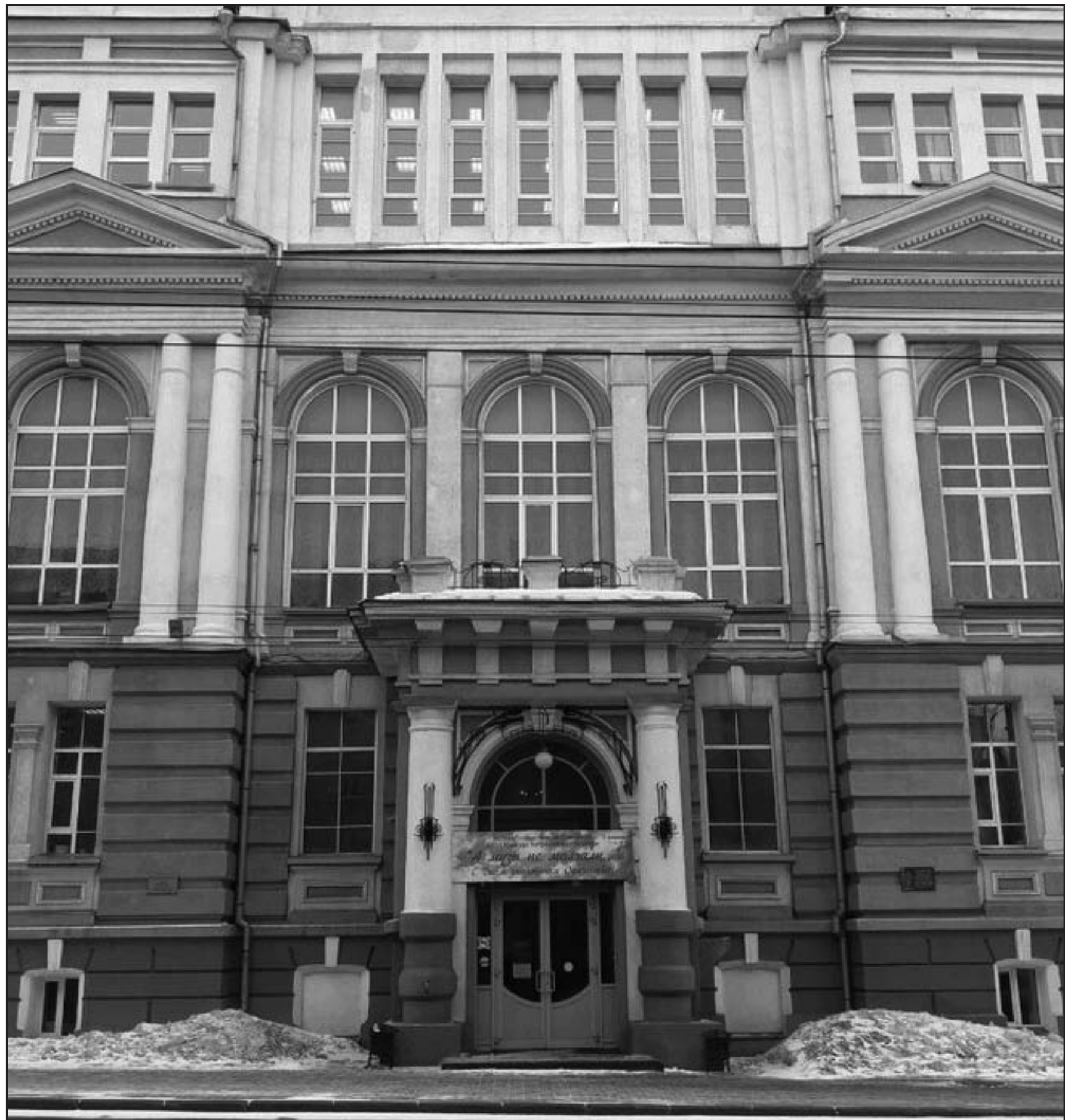

Курский государственный университет 